\title{
CORRIGENDUM
}

\section{Can we shorten the lactose tolerance test?}

JL Domínguez Jiménez and A Fernández Suárez

European Journal of Clinical Nutrition (2014) 68, 642; doi:10.1038/ejcn.2014.48

Correction to: European Journal of Clinical Nutrition (2014) 68, 106-108; doi:10.1038/ejcn.2013.240; published online 27 November 2013

Since the publication of this paper, the authors have realized that there is an error in the legend of Figure 1 where Pathological and Normal should be the other way around.

The corrected Figure 1 is shown here.

The authors apologize for any inconvenience caused.

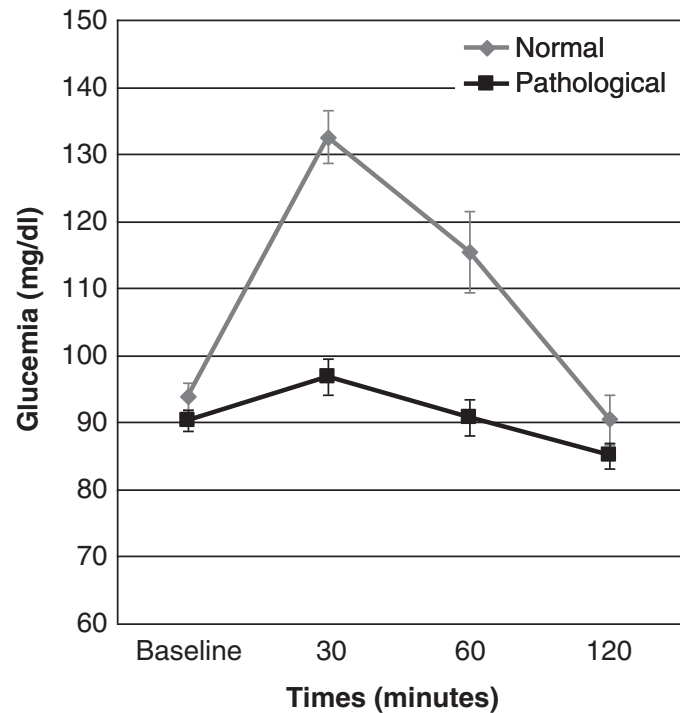

Figure 1. Comparison of average blood glucose levels at different times between normal and pathological classic LTT with confidence interval at $95 \%$. 